I Universidade Estadual de Campinas (Unicamp),

\title{
A HISTÓRIA NUNCA SE FECHA ${ }^{1}$
}

A expressão circuito fechado usada por Florestan Fernandes assume posição central em seus estudos sobre a sociedade brasileira, constituindo-se em um dos apoios teórico-metodológicos de sua reflexão. Tive oportunidade de apontar em texto anterior (Bastos, 2002) que a recusa às interpretações dualistas que definem o Brasil formado por partes que se opõem - atraso/moderno, velho/ novo, retardo/avanço - configura o ponto de partida para essa formulação. Trata-se de resposta crítica a uma visão do país que fundamenta propostas sobre mudança social, econômica e cultural que elegem o controle autocrático como direção do processo proposto para transformar os setores atrasados em áreas modernas. O modo pelo qual se define a necessidade de superação do denominado atraso automaticamente estabelece não apenas o perfil do grupo político dirigente, mas a própria forma de exercício do poder. Ou seja, Florestan Fernandes mostra que o diagnóstico construído a partir de uma perspectiva apoiada no dualismo determina as medidas a tomar, quem as deve aplicar, como as implantar. Estaria assim previamente definido o lugar dos atores políticos e justificadas medidas repressivas se necessário, para o alcance dos objetivos propostos. Estaria pronta a agenda política; o circuito está fechado. Voltarei a esses pontos mostrando como concretamente o autor os aborda.

Indiquei que a expressão circuito fechado se refere a uma circunscrição teórico-metodológica, pois Florestan (I979: 5) afirma que "constitui uma equação metafórica de um dos ângulos da situação que prevalece graças aos tempos 
retardados da revolução burguesa". Ao empregá-la afasta a concepção de que a sociedade teria destino traçado ou, ainda, qualquer sugestão de que ela é por definição estática, tendo já determinado seu status político e/ou sua estratificação social. Ou seja, o autor recusa o desenho de um futuro que desconheça a possibilidade de agência capaz de intervir na alteração da estrutura social. Em suas palavras, "a história nunca se fecha por si mesma e nunca se fecha para sempre” (Fernandes, I979: 5). Mais do que isso, trata-se de afirmação sobre sua visão do papel da sociologia, que não se pode contentar com uma análise fragmentadora da sociedade, mas deve operar a partir da articulação entre história e totalidade. Constatação dessa posição verifica-se no livro Circuito fechado, publicado em I 976 com o subtítulo Quatro ensaios sobre "poder institucional", no qual retoma a relação entre o Estado autocrático e o controle da modernização. ${ }^{2} \mathrm{Na}$ orelha da segunda edição o autor explicita: "o título e o subtítulo da obra situam a ligação dos dois temas e seu sentido global. [...] Ao se fechar às pressões democráticas de baixo para cima, a sociedade de classes da América Latina exclui o Povo da história" (Fernandes, I979: orelha). Como se pode perceber, refere-se ao desmonte dos movimentos sociais, iniciados no final dos anos I950 e início dos I960, pelo golpe de I964 no Brasil, e à continuidade da repressão sobre manifestações que se seguem, além de a situações semelhantes em vários países latino-americanos que no mesmo período também conheceram governos ditatoriais.

Assim, Florestan Fernandes considera os limites das análises institucionalistas desarticuladas de uma visão ampla da sociedade, uma vez que a configuração das instituições é resultado do embate das forças sociais e efeito da vitória não democrática, tanto no Brasil como na América Latina, de apenas um conjunto delas. Nesse arcabouço de forças coloca com destaque as ideias, mostrando que elas fundam, além das transformações do quadro social, o lugar dos intelectuais e a emergência de novos atores políticos. Referindo-se aos fundamentos das mudanças não democráticas no Brasil de I964, argumenta:

Muitos se lembram de que não há revolução sem teoria revolucionária. Contudo, também não há contrarrevolução sem teoria contrarrevolucionária. O mínimo que se pode afirmar, sociológica e historicamente, é que os intelectuais - tanto os "liberais", quanto os "conservadores" e "reacionários", de mistura com muitos "reformistas" inconsequentes - colaboraram com essa chamada "revolução institucional” (?!)3 (Fernandes, 1979: 3, grifo do autor)

Os obstáculos colocados à emergência de novos atores sociais não se referem apenas ao receio de sua atuação política por meio de mobilização. Trata-se também de uma forma sutil de repressão disfarçada para fugir à acusação de censura. Consiste em um arranjo institucional que retira aos subalternos seu lugar de fala. Não só; também para os intelectuais e artistas é limitado ou desqualificado o espaço de denúncia, procedimento que atinge diretamente a divulgação das ideias. 
A atualidade do texto me surpreende, principalmente porque, em um dos ensaios do livro Circuito fechado, ${ }^{4}$ está descrita e analisada a intervenção feita no decorrer dos anos I 960 na universidade e no âmbito da arte, que levou ao afastamento de suas atividades vários professores e artistas considerados perniciosos ao regime. O ensaio evidencia como educação e cultura são campos importantes de debate sobre a democracia e como o controle autocrático sobre essas áreas constitui-se em obstáculo à emergência de novos atores sociais e políticos vistos como ameaças à manutenção do status quo. Lembro o sentido atual do texto embora saiba que as situações não se repetem ipsis literis. Sei que primeiramente aparecem como drama e podem reaparecer como comédia, mas os dois efeitos são trágicos. Analisando o jansenismo, Lucien Goldmann (I959) mostra como se explicita a tragédia uma vez que alguns grupos sociais não encontram mais lugar na sociedade, ou seja, vivem o paradoxo de simultaneamente estar e não estar no mundo por não contar com um espaço histórico para o exercício de seus princípios e valores. Invocando linguagem contemporânea, vivem em um cenário de não reconhecimento.

\section{ABORDAGEM TEÓRICO-METODOLÓGICA}

A linearidade fundante das interpretações dualistas se constitui no ponto crítico da proposta teórico-metodológica contida na expressão circuito fechado. A visão linear também sustenta a sugestão de evolução social, uma vez que a "sociedade atrasada", graças ao controle das mudanças sociais pelos setores dominantes, poderia atingir um estágio progressivo. Essa formulação é refutada por Florestan Fernandes pelo questionamento da existência de um continuum progressista no processo de transformação social. Propondo operacionalização da pesquisa e suporte teórico à sua interpretação, toma o termo continuum e mostra a alteração de seu sentido. O efeito linear é superado; o autor "opera como se as duas pontas do continuum se encontrassem e esse encontro gerasse, simultaneamente, o objetivo, a unidade de pesquisa, o desafio à compreensão, a busca de um suporte teórico e o método de investigação" (Bastos, 2002: I 86) O fechamento do circuito ganha conotação ampla: além de ponto de partida, avança em direção ao resultado da investigação, justificando abertura de espaço para propostas de redirecionamento da mudança social. ${ }^{5}$ Do ponto de vista metodológico afasta-se de formulação puramente causal, abrindo-se para a indagação dos efeitos provocados pela estrutura social, relações sociais, emergência/ação dos atores, instituições, normatização e comportamento autoritário, permitindo ainda o questionamento sobre quem se apropria das mudanças provocadas e é por elas beneficiado.

Certamente é uma ousadia, risco que ele admite, principalmente ao se justificar contra os ataques sofridos pela sociologia crítica que ele propõe após as medidas assumidas pelo governo militar em I 968 , em parte reforçadas pelo comportamento de alguns grupos políticos. Indaga sobre os limites impostos 
para pensar "o que é uma sociedade de classes da periferia na era do capitalismo monopolista" (Fernandes, I976: 9). Ou ainda, reivindica liberdade de "procurar os 'tempos internos' de uma modernidade tão peculiar, que se desata 'de fora para dentro' e dá origem a uma 'orgia institucional'” (Fernandes, I 976: 9). Coloca-se em perspectiva oposta às "fórmulas da 'ciência política sistemática', à direita, ou do 'estruturalismo marxista', à esquerda” (Fernandes, I976: 9). ${ }^{6}$

Recusar o caminho de análise linear da história brasileira e latino-americana significa retomar o exame dos processos de longa duração ao lado da situação presente para compreender as razões de permanência de sociedades marcadas pela pobreza, pela desigualdade, pela exclusão e caracterizadas pela histórica situação de concentração de riqueza e má distribuição de bens. Trata-se de objeto incômodo, reconheço, mesmo porque o método propicia uma análise não só interna do modelo, mas o articula ao movimento internacional da economia, da sociedade e da política. Mais ainda, permite perceber o processo de reprodução e de autoconsolidação da sociedade de classes no Brasil.

Essa recusa o coloca em uma posição diferenciada em relação às reflexões do período sobre os vários aspectos da sociedade brasileira, por isso define objeto e método que denominei incômodos. Autores como Gilberto Freyre (I933), Caio Prado Jr. (I972), Celso Furtado (2005), Antonio Candido (I98I), para indicar alguns deles, centralizam suas pesquisas em torno da ideia de formação.7 Muito apropriadamente Gabriel Cohn (2015: 42) lembra que Florestan

não usa esse termo porque no fundo está pensando sempre a deformação, a dificuldade da formação, eu quase diria que a areia nas engrenagens históricas dessa sociedade; dessa sociedade sim, porque ele não está pensando a sociedade em geral, mas, nos termos muito expressivos que ele mesmo usa, o ainda, o aqui e o agora.

Palavras que aparecem constantemente em seus textos - tensão, dilema, desafio - explicitam essa orientação. O termo dilema ganha especificidade em várias passagens das pesquisas de Florestan, afastando-se da visão do senso comum. "Os sociólogos entendem por 'dilema' um tipo de inconsistência estrutural e dinâmica que nasce da oposição entre o comportamento social concreto e os valores morais básicos de determinada ordem social" (Fernandes, I976b: 208). Assim, em situações concretas os dilemas são vistos de acordo com o padrão civilizatório da sociedade: como "estado natural das coisas" ou como uma "transição conjunturalmente vantajosa", em perspectiva conservadora ou inconformista, respectivamente. Florestan mostra que a primeira está referida a uma visão de ajuste das esferas tradicionais da sociedade brasileira àquelas que se transformaram com mais intensidade. De certo ponto de vista, indica que é possível a superação da naturalização dos conflitos e que a sociedade pode abrir-se para a conscientização sobre eles. Ou seja, a aceitação da existência do conflito como legítimo, com base na situação dos grupos sociais, representa um passo na direção da democracia. Fazendo forte crítica à sua própria 
formulação, confessa ter ele mesmo, em certo momento, aceitado essa visão a partir do emprego de análise assentada no princípio da "demora cultural", a qual reflete bastante a visão do senso comum, marcada pelo caráter dualista. ${ }^{8}$ Mesmo seu modo de percepção da ordem social competitiva tem a ver com esse afastamento da visão histórica linear. Assim, seu método, além de se constituir em instrumento de abordagem do objeto, articula unidades empíricas de análise que em geral são enfocadas autonomamente.

As considerações a respeito das controvérsias sobre método já aparecem desde os primeiros textos de Florestan Fernandes. ${ }^{9}$ O livro Fundamentos empíricos da explicação sociológica, publicado em I959 (Fernandes, I967), traz uma visão ampla sobre por que contrapõe o alcance e os limites analíticos de diversas tradições na teoria sociológica. ${ }^{\text {10 }} \mathrm{O}$ capítulo sobre o funcionalismo é exemplar desse procedimento. ${ }^{\text {II }}$ No conjunto dos textos demonstra que divergências metodológicas entre autores expressam oposições fundamentais sobre tema e análise decorrente.

Sabemos que o método é um campo de conflito; contudo, uma vez que se aceite ser o objeto também definido com recurso a ele, na mesma direção deve-se admitir que o conteúdo é imanente. Não se trata de escolher como um dado da natureza o que vem antes ou depois, o ovo ou a galinha. A unidade empírica da pesquisa decorre de uma tomada de posição prévia, que tem a ver com a pergunta que se faz: queremos prever qual será o comportamento de um grupo diante de uma situação nova? pretendemos analisar qual a relação causal de ações e relações racionais em um contexto atravessado por crise que permite a emergência de comportamentos tradicionais aparentemente já superados? buscamos saber quais efeitos de certas práticas sociais, econômicas, políticas ou culturais reforçam ou questionam uma formação econômico social? Entre outras possíveis, são perguntas perfeitamente legítimas que visam à compreensão de aspectos importantes dos problemas que ocorrem na sociedade. Em cada um dos casos citados a unidade empírica que define a pesquisa é diferente. O primeiro fixa-se no grupo social; o segundo, na ação social; no terceiro a investigação parte da análise da formação econômico-social. Essas questões podem ser formuladas em conjunto, o que determina a amplitude da pesquisa e a aplicabilidade da resposta. É óbvio que a aceitação dessa posição que articula teoria e método recusa a propalada objetividade só presente na pesquisa meramente quantitativa. Em outros termos, a própria definição do objeto empírico carrega em si uma posição diretiva.

Florestan Fernandes prioriza a pergunta sobre os efeitos sociais e políticos advindos de uma formação econômico-social na periferia do capitalismo, formação peculiar, pois não apenas soma, mas combina, na manutenção de seu perfil, modernidade e arcaísmos. A pergunta sobre a coexistência no Brasil de capitalismo moderno e desigualdade, que limita o acesso aos direitos políticos e sociais, o induz a avançar no estudo tanto dos grupos como das modalidades 
de ação. A emergência de elementos tradicionais que convivem ao lado da modernização é ocorrência comum em várias sociedades. O que torna original a formulação de existência de um circuito fechado e a compreensão de seu funcionamento é a constatação das formas de combinação que operam de modo a que setores econômicos e sociais historicamente subalternos atinjam um nível de modernização semi-integrado e ao mesmo tempo excludente. É uma forma sui generis de reprodução da desigualdade. Uma modernização que não os torna igualmente competitivos em relação às demais classes sociais.

A escolha do método não é arbitrária, não é mero acidente no percurso da pesquisa e, desse modo, é a eleição de um entre outros instrumentos que permite encaminhar a resposta à pergunta que se colocou originalmente, como já indicamos. Assim, como consequência à indagação sobre os efeitos da formação econômico-social situada na periferia do capitalismo, Fernandes propõe a questão: como no Brasil o processo de modernização incorpora a mecânica do atraso, procedimento que, em tese, caminharia em direção contrária à racionalidade da modernização? Não se trata de preocupação comum às análises que constatam a presença de comportamentos ou ações tradicionais em um processo direcionado pela racionalidade capitalista/burguesa. A peculiaridade encontra-se na presença de outro funcionamento, de uma marca específica de ordenação social em que a mecânica do atraso compõe o processo de modernização. Assim, para explicar a ordenação política é fundamental a compreensão dos vaivéns da sociedade. Como indiquei, não se trata de constatação do atraso, mas da análise da adoção da mecânica que controla simultaneamente modernização e atraso. É nesse caminho que se encontram as bases da adoção do termo autocracia, referente às formas de organização do poder assentadas em elementos que se colocam além das normas fundantes das instituições. ${ }^{\mathrm{I} 2}$

Florestan Fernandes considera fundamental recuperar na pesquisa esse fundamento. Assim, pergunta como se dá a reprodução da vida nos diversos grupos sociais, sendo esse o processo social decisivo para se apreender tanto a permanência como a transformação da estrutura social. O estudo sobre as formas de socialização embasa sua investigação em A integração do negro na sociedade de classes (Fernandes, I965); não se limita, porém, a formular a questão em termos de identidade individual, mas avança na direção das condições ou limites à integração social das diferentes camadas da população. Aqui, ainda, não se contenta em analisar os processos de assimilação, adaptação do grupo no caminho da integração à sociedade envolvente. Seu horizonte se projeta além do grupo ou da comunidade, caminha na direção da ordem social competitiva, um dos pilares das transformações burguesas. Trata-se da linha analítica que preside o referido livro.

Mesmo questionando a eficácia dessa ordenação, ${ }^{13}$ analisa a existência ou não de igualdade de condições de competição para os diferentes grupos considerados em oposição, brancos e negros, pobres e ricos. A campanha em 
defesa da escola pública que Florestan protagonizou representa claramente a definição de uma via de alcance da superação da desigualdade e da equalização, embora parcial, das condições de competição. Nos trabalhos que abordam a assimetria da situação e das relações de negros e brancos, o autor não indica qualquer política pública para alteração da situação. De modo muito diferente, mostra os movimentos negros ao longo da história posterior à abolição acentuando como sua atuação construiu a percepção de uma visível situação discriminatória na sociedade brasileira. Tratando-se de constatação de situação concreta porque envolve comportamentos e atitudes, e não tendência genérica como seria a simples admissão da existência do preconceito, a agência impele a mobilização dos negros a um patamar democrático. Tornam-se sujeitos da mudança social. Embora o processo seja lento, com rupturas provocadas nos períodos ditatoriais ou pela autocracia que marcou quase todos os governos no Brasil, a evolução crítica é positiva. $\mathrm{Na}$ análise desse processo lembro que o papel dos denominados depoentes no livro $\mathrm{A}$ integração do negro na sociedade de classes tem centralidade na pesquisa. ${ }^{\mathrm{I}}$

A referência sobre o debate interno nos coletivos negros organizados em associações e/ou movimentos sociais, assim como a exposição sistemática das condições de existência social por alguns desses participantes no desenrolar da pesquisa, levou os componentes a expressar o sentido da exclusão contido no próprio processo de socialização que vivenciaram. Mais ainda, propiciou a alteração do repertório discursivo e de ação nas mobilizações (ver Bastos, 20I5a). Um passo em direção ao desenho de uma sociedade democrática. Assim, a consciência de que a reprodução da vida é um processo social decisivo que define não só o lugar do indivíduo na sociedade, mas sua possibilidade de ação permite aos movimentos negros diagnosticar a liberdade formal obtida pela abolição da escravidão como insuficiente, pois a situação do negro no conjunto das forças sociais, sendo assimétrica em relação aos brancos, repõe o status quo. Nessa constatação os coletivos negros operaram, como mostra Florestan Fernandes, e o fazem ainda hoje no Brasil, buscando instrumentos que abram a possibilidade de eles se tornarem, ao lado de outros atores sociais, sujeitos das mudanças.

Trata-se de importante percepção que, embora estivesse presente nos anos I950 e início dos I960, não pôde naquele momento, via ação daqueles coletivos, ganhar corpo na institucionalização de medidas políticas em razão do longo cenário da repressão, mas seguiu alimentando a consciência possível desses grupos que continuaram a intervir na sociedade mediante ações políticas menos visíveis ${ }^{15}$ - voltam, contudo, a ser visualizadas no quadro que anuncia a abertura política dos anos I980 e são incorporadas nos debates ocorridos no processo constituinte, e prosseguem até hoje. Então, por meio da coletivização dos problemas, emerge a pergunta: como participar da elaboração das agendas política, social, cultural? Muitas respostas são dadas a essa questão, sendo que algumas delas serão objeto de políticas públicas posteriores e se constituirão em ação prioritária dos coletivos negros no Brasil do século XXI. 


\section{ATUALIDADE DO PROCEDIMENTO}

A formulação da categoria circuito fechado estaria limitada a dar conta apenas de um período da história da sociedade brasileira circunscrita ao momento da produção da obra de Florestan Fernandes, principalmente àquele em que se inscrevem suas propostas teórico-metodológicas? Ou podemos reconhecer atualidade na sua utilização como instrumento analítico extensível a outros períodos da vida brasileira? Para averiguar a adequação de seu emprego na sociedade brasileira atual, consideradas as afirmações anteriormente deste texto, um procedimento coerente será retomar as questões indutoras de sua pesquisa e refletir sobre elas a partir dos desafios contemporâneos.

No primeiro parágrafo deste texto destaco a crítica do sociólogo paulista à interpretação dualista da sociedade brasileira, mais precisamente, à existência de dois Brasis. ${ }^{16}$ A recusa de admissão desse diagnóstico por Florestan Fernandes, conforme já indicamos, ancora-se na constatação da realimentação entre os setores: o moderno, com concentração de renda, mantém as margens pauperizadas para a dupla reprodução. Essa troca se dá entre regiões, etnias, camadas da população, cidades (periferia/bairros centrais). Não se trata de uma região, de um grupo social, de um setor da população atrasados que "precisam avançar”, mas que são mantidos numa condição assimétrica para que regiões, grupos ou setores continuem a vivenciar privilégios.

Ainda hoje a assimetria econômica e social entre as regiões no Brasil é continuamente denunciada pelos dados estatísticos de renda per capita, salários, ou considerando-se a qualidade de vida medida pelo índice de desenvolvimento humano (IDH). ${ }^{17}$ A desigualdade econômica e social entre negros e brancos pode ser verificada nos índices publicados em novembro de 2019 pelo Instituto Brasileiro de Geografia e Estatística (IBGE) sobre salários, participação no mercado de trabalho, distribuição de renda, violência e representação política. ${ }^{18}$ Segundo dados da Carta Capital de dezembro de 20I9, o Brasil é o segundo país do mundo com maior concentração de renda: os I\% mais ricos concentram $28,3 \%$ da renda total. ${ }^{19}$ Os dados deixam o Brasil atrás somente do Catar, onde a proporção é de $29 \%$. Nesses dois países quase um terço da renda está nas mãos dos mais ricos.

Embora esses dados se refiram ao Brasil, é patente a existência dessas situações em grande parte do mundo, o que demonstra a possibilidade de aplicação mais ampla da reflexão sobre o circuito fechado proposta por Florestan Fernandes para a análise da sociedade. O que também permite afirmar que a periferia não está apenas no hemisfério sul, não é dado territorial, mas referese às margens da sociedade.

Volto a alguns elementos já levantados, sem pretender esgotar a argumentação. A expressão circuito fechado está referida a uma forma de restrição democrática que não se limita ao exercício do voto ou à chamada normalidade institucional. O arranjo do poder permite o arbítrio em relação às instituições 
e à própria ordem social competitiva, construindo um princípio ordenador antidemocrático que atravessa historicamente a sociedade brasileira. Florestan traduz esse processo com a elaboração do termo autocracia. ${ }^{20}$

É fácil verificar que no Brasil atual tanto a naturalização da desigualdade quanto a forma pela qual o Executivo federal dimensiona a crise na área da saúde ressoa a permanência desse princípio antidemocrático. Uso o termo antidemocrático em lugar de não democrático para acentuar que se trata não apenas de uma situação transitória, mas de um processo que busca ordenar a sociedade brasileira e que pesa mais quando se dá a presença de grupos conservadores no poder. Constatamos uma repressão que pretende ser sutil para evitar a acusação da existência da censura, mas que se torna evidente ao desqualificar a educação, a cultura, a mídia e até mesmo a ciência, como já apontamos. Esse procedimento retira o lugar de atuação dos agentes questionadores da ordenação político-social, o que é grave do ponto de vista tanto ético como político, uma vez que por meio do discurso de certas personalidades públicas reforça-se a naturalização da desigualdade pelo conjunto da população brasileira. No final dos anos I950 e início de I960 discutia-se a situação ao mesmo tempo que as mobilizações sociais denunciavam a assimetria das condições de existência entre as classes representadas na pirâmide social; hoje a repressão disfarçada funda a ocultação desses dados via desqualificação da mídia ou dos estudos acadêmicos que os apresentam.

A insistência no termo antidemocrático tem a ver com a constatação de que os avanços democráticos conquistados nas últimas décadas não têm firmes raízes no comportamento social e político no Brasil. Ou seja, mesmo recalcada, continua presente "a velha sociedade brasileira, historicamente marcada por valores e práticas sociais e culturais autoritários de socialização e de orientação das condutas, de afirmação de hierarquias nas mais diferentes relações sociais e de reiteração das desigualdades" (Botelho, 20I9: I8).

Essa questão nos permite indagar sobre o papel representado pela tradição sociológica derivada das propostas de Florestan Fernandes nos dois períodos indicados: o primeiro, entre o final da década de 1950 e início da seguinte; o segundo considerando a produção sociológica atual.

O primeiro momento, no qual as bases da formulação teórica de Florestan se consolidam, traz forte diálogo com as interpretações sociológicas anteriores e a colocação de elementos que as fundamentam. Já indiquei sua crítica às análises microssociais sem articulação com a sociedade mais ampla. Assim, advoga a articulação das visões micro e macrossociais, ponto muito importante em sua formulação teórica (ver Bastos, 20I8). É nessa direção que explicita o emprego simultâneo do estrutural-funcionalismo e da sociologia histórica. "A análise funcional, repito, é instrumental. [...] Se for estudar [...] as transformações que ocorrem 'através' e 'além' da repetição da ordem, a análise estruturalfuncional é largamente complementada pela análise histórica” (Fernandes, I978: 
I06). Direciona sua crítica aos estudos que interrompem a análise no momento descritivo "como se tem feito em muitos estudos antropológicos e sociológicos de comunidades, da empresa industrial, da escola etc." (Florestan, I978: I06).

O diálogo, portanto, não é somente com a sociologia, mas com seus efeitos no contexto em que foi produzida. Seu alcance e seus limites. O período compreendido entre meados dos anos I950 e início dos I960 é marcado por grandes debates sobre temas como fome, pobreza, marginalidade, que ocuparam grande parte da reflexão das ciências sociais latino-americanas e mobilizaram projetos políticos para seu enfrentamento. Não só as discussões sobre a temática, mas também as propostas e alianças políticas celebradas localizaram-se em pontos bastante variados do espectro ideológico, provocando enfrentamentos de diferentes ordens. No caso brasileiro trata-se de momento marcado por vários movimentos sociais advindos das diversas regiões do país: movimentos operários, mobilizações em torno da urbanização/habitação, reivindicações sobre programas de saúde, defesa da escola pública, lutas pela reforma agrária. ${ }^{2 I}$ Aqui, para salientar um dos efeitos importantes da sociologia crítica de Florestan Fernandes, lembro a preeminência dos movimentos dos trabalhadores rurais, que simultaneamente reivindicavam a extensão dos direitos trabalhistas ao campo e o acesso à terra via alteração da estrutura agrária marcada pelo latifúndio. Se não de forma direta, a privação de direitos humanos fundamentais é amplamente denunciada pela miséria conhecida por essa população. Por exemplo, a grande seca que atingiu o Nordeste, em especial os estados do Piauí, Ceará, Rio Grande do Norte, Paraíba e Pernambuco, foi amplamente divulgada pelos jornais. O êxodo em direção às cidades foi grande, sendo que os denominados flagelados constituíram a maior parte da população que se localizou nas favelas do Rio de Janeiro e São Paulo.

Sem entrar em pormenores, lembro esse cenário para apontar o papel das várias forças sociais que operaram no questionamento tanto da estrutura social como dos arranjos políticos que a sustentavam. Somando-se a elas, a sociologia crítica de Florestan Fernandes desempenha uma função importante ao analisar os sustentáculos dessa situação, demonstrando o sentido histórico do conflito e legitimando seu questionamento. Assim, creio ser possível afirmar que suas ideias ganharam lugar importante no desmonte do pacto agrário-industrial dos anos I930 que, naquele momento e nos imediatamente posteriores, direcionou a modernização do país excluindo do processo grande parte da população, principalmente os trabalhadores rurais, que não tiveram seus direitos trabalhistas reconhecidos e ficaram proibidos de associação via sindicatos (ver Bastos, I984). A discussão da questão fundiária foi adiada sine die. O efeito do duplo adiamento teve conhecidas consequências. De um lado, a ausência de legislação permitiu a extensão do arbítrio na regulação das relações do trabalho no campo. A prorrogação da discussão sobre a concentração de terras permitiu que, com a localização da capital federal no planalto central, se realizasse um 
avanço das fronteiras econômicas na direção da Amazônia, multiplicando a possibilidade de estabelecimento de grandes propriedades. Interpretou-se que o avanço da fronteira econômica se dava em um vazio demográfico. Indígenas, seringueiros, povos da floresta foram sacrificados não só com o desaparecimento como pela mudança de suas condições de existência social. Assim, a aliança política que estava posta em xeque no final dos anos I950 e início de I960 refez-se, após o golpe de Estado de I964, em outros termos porque foi ampliado seu raio de ação garantida pela forte repressão às mobilizações sociais, ao pensamento independente da universidade, à perseguição de artistas e intelectuais. Florestan Fernandes e seu grupo de pesquisadores foram afastados da Universidade de São Paulo pelo Ato Institucional (AI5) do governo militar. Seu pecado foi mostrar que existe a anterioridade do conhecimento da sociedade sobre o desenho das mudanças econômicas e políticas. É verdade que esse procedimento, como infelizmente sabemos, pode ser desdenhado, mas isso só pode ocorrer em um cenário antidemocrático.

A pergunta que se coloca hoje para a tradição intelectual que elege, como fazia Florestan, o princípio emancipatório como prioritário à reflexão sociológica brasileira, é como continuar a reflexão e utilizar instrumentos analíticos em face dos novos dilemas do país. Encontro um promissor encaminhamento em alguns debates que acompanhei nos últimos anos que propõem o retorno da sociedade para embasar a política e o Estado, questionando a ideia "de que as inovações institucionais seriam capazes, por si mesmas, de transformar a dinâmica social, como se os processos políticos existissem exclusivamente no âmbito sistêmico e, portanto, que as instituições possam ser consideradas variáveis independentes da vida política" (Botelho, 2019: I7).

Retornar à sociedade significa assumir o risco de conhecer, de visualizar os mecanismos de funcionamento dos processos sociais, de reconhecer as características diferenciais dos atores sociais, admitir que existem conflitos de interesses, que a presença de privilégios elege políticas discriminatórias em relação a eles. Mais, ter coragem de atrever-se a pensar (sapere aude) ${ }^{22}$ para saber e não apenas contentar-se em perguntar: e daí?

Recebido em 3/7/2020 | Aprovado em 31/7/2020

Elide Rugai Bastos é livre-docente em pensamento social

pela Universidade Estadual de Campinas (Unicamp), onde é professora titular. Recebeu o Prêmio Anpocs de Excelência Acadêmica Antônio Flávio Pierucci Sociologia, em 20I7. É autora de, entre outros livros, As criaturas de Prometeu (2006). 


\section{NOTAS}

I Este artigo é parte de uma pesquisa PQ financiada pelo CNPq.

2 Essa questão já fora abordada de forma breve no livro Mudanças sociais no Brasil, de I96o (Fernandes, I960), e, mais tarde, nas diversas revisões feitas nas edições posteriores; com mais profundidade ele a enfrenta em A revolução burguesa no Brasil, de I975 (Fernandes, 1976).

3 Os pontos de interrogação e de exclamação não foram acrescentados por mim; são do próprio texto de Florestan Fernandes. Creio que a sinalização feita pelo autor referese ao fato de não se tratar de revolução, mas de golpe militar, com a manutenção da "velha ordem".

4 Trata-se do capítulo IV, "A universidade em uma sociedade em desenvolvimento". São suas palavras: "A universidade sempre esteve em relação tensa com os estratos dominantes e com o obscurantismo na América Latina. Mesmo a 'universidade tradicional' não escapou à incompreensão e a algumas represálias, que certas vezes atingiram seriamente os elementos mais representativos do corpo docente ou as tentativas mais ousadas dos estudantes" (Fernandes, I979: I44).

5 Como veremos adiante, Florestan não indica formas específicas de políticas sociais, uma vez que acentua a importância da emergência democrática dos sujeitos das mudanças.

6 Lembro que Theodor Adorno (2008: 22I-222), ao discutir os limites da análise circunscrita apenas ao institucional, afirma a necessidade de duas formas analíticas articuladas: a imanente e a que leva em consideração os efeitos das normas.

7 Gilberto Freyre em Casa-grande \& senzala. Formação da família brasileira sob o regime de economia patriarcal, de I933; Caio Prado Jr. em Formação do Brasil contemporâneo, de I942; Celso Furtado em Formação econômica do Brasil, de I959; e Antonio Candido em Formação da literatura brasileira, de I959.

8 "Que tal ilusão tenha interferido nas ideias de alguém que compreendia essa mesma realidade através de categorias sociológicas e não tinha dúvidas em apontar a inadequação estrutural e dinâmica do horizonte cultural dominan- 
te constitui algo digno de ponderação. Isso quer dizer que estamos de tal maneira impregnados daquelas manifestações simbólicas de teor compensatório, que o próprio cientista social precisa percorrer um caminho difícil para libertar-se de pré-noções e chegar a assumir uma posição favorável à descrição objetiva das coisas" (Fernandes, I976b: 2I0-2II).

9 Em trabalho de aproveitamento escrito em 1946 para o curso de Emilio Willems, em que discute a concepção política de Mannheim, a preocupação com a metodologia já está presente (Fernandes, I970); em suas pesquisas sobre os Tupinambá, em sua dissertação de mestrado e sua tese de doutorado, a questão metodológica é discutida em relação às fontes que servem de base para seus dados; o "Ensaio sobre o método de interpretação funcionalista em sociologia", apresentado em seu concurso de livre-docência em 1953 representa um dos clássicos sobre a temática metodológica.

Io A respeito da antecipação de Florestan na consideração de Marx como uma das matrizes da sociologia faço comentários no texto "Uma sociologia local e cosmopolita" (Bastos, 20I5).

II Robert K. Merton (I964: 93) considera esse trabalho de Florestan Fernandes informativo e sistemático.

I 2 Em livro recente, André Botelho (20I9: I7) lembra a importância dessa tradição intelectual: "Recolocando a política e o Estado na sociedade, a tradição intelectual aqui apresentada problematiza a ideia de que as instituições sejam espaços de ação autônoma em relação a valores e às práticas sociais vigentes na sociedade".

I3 Na nota explicativa desse livro, ele afirma: "A escolha da ordem social competitiva, como foco de referência das observações, não nasce de qualquer convicção do autor de que ela seja uma ordem social natural" (Fernandes, I965: XIII).

I4 A pesquisa organizou-se com a participação de vários coletivos negros a partir de reuniões feitas na Biblioteca Municipal. Como, segundo Bastide (Bastide \& Fernandes, I955: I2), "tais reuniões não podiam compreender senão líderes, intelectuais ou pessoas de classe média [deixan- 
do] de lado a classe baixa, que constitui o grosso da população de cor", estes serão visitados pelos alunos-pesquisadores nos bairros, cortiços. Assim, se aplicam questionários, realizam-se entrevistas ocasionais ou formais, coletam-se biografias e histórias de vida. "Procuramos buscar a colaboração direta e crítica dos sujeitos da investigação, [...] cujos sentimentos e orientações de comportamento eram mal conhecidos [...] [essa colaboração] foi maciça: nos seminários contávamos com uma afluência média de I30 a I50 pessoas" (Fernandes, I979: 65). Campos (2013) relata os diversos passos da pesquisa.

I5 Em A descoberta do insólito, Silva (2013) relata os diversos momentos desse procedimento.

I6 A intervenção de Florestan Fernandes (I959), "Atitudes e motivações desfavoráveis ao desenvolvimento", no Seminário Internacional Resistências às Mudanças - fatores que impedem ou dificultam o desenvolvimento, do Centro Latino-americano de Pesquisas em Ciências Sociais, em I959, questiona a tese dos dois Brasis. Exponho essa argumentação em Bastos (20II).

I7 $O$ índice de desenvolvimento humano avaliando renda, educação, saúde é muito desigual se compararmos as regiões do Brasil. Dados recentes evidenciam que a região Sudeste tem o maior IDHM do país, com valor de 0,766 . Em segundo lugar está a região Centro-Oeste, com IDHM de 0,757 , praticamente empatada com a região Sul, terceira colocada, com IDHM de 0,754 . As regiões Norte e Nordeste têm os menores IDHM do país, com o,667 e o,663, respectivamente. Ver <https://www.archdaily.com.br/br/ 784994/diferenca-de-idhm-entre-regioes-brasileiras-diminuiu-nas-ultimas-decadas $>$.

I8 Em levantamento do IBGE, a população que se declarou preta e parda, em 20I8, representa 55,8\% da população brasileira. A diferença entre os salários dos brancos em relação aos dos negros é de 73,9\%. Com relação à inserção no mercado de trabalho ela também é gritante: $64,2 \%$ da população desocupada e 66,1\% da subutilizada é de pardos e negros. A distribuição de renda segue o mesmo padrão: negros e pardos representam $75,2 \%$ do grupo formado pelos Io\% de indivíduos com os menores rendimentos do país. A taxa de homicídios entre a população de pretos e pardos de I5 a 29 anos 
do sexo masculino entre 2012 e 2017 é de 185 por Ioo mil habitantes. Apenas $24,4 \%$ dos deputados federais e $28,9 \%$ dos deputados estaduais são pretos ou pardos, o que constitui forte desigualdade na representação política (Rosa, 20I9)

I9 Disponível em <www.cartacapital.com.br > sociedade , desigualdade-brasil- 9 de dezembro de 20I9>. Acesso em 2I maio 2020.

20 Para uma visão mais aprofundada dessa questão, ver Botelho \& Brasil Jr. (2020).

2I Não me estendo aqui sobre essa questão, que focalizei no artigo "Atualidade do pensamento social brasileiro" (Bastos, 20II).

22 A expressão proposta por Horácio foi ampliada por Kant e passou a ser usada como lema do Iluminismo. Contemporaneamente foi empregada por Foucault no sentido de ousar saber.

\section{REFERÊNCIAS BIBLIOGRÁFICAS}

Adorno, Theodor. (2008). Introdução à sociologia. Tradução de Wolfgang Leo Maar. São Paulo: Editora Unesp.

Bastide, Roger \& Fernandes, Florestan. (1955). Relações raciais entre negros e brancos em São Paulo. São Paulo: Unesco/ Anhembi.

Bastos, Elide Rugai. (20I8). Actualidad del pensamento social brasileño. In: Brigel, Breno \& Brasil Jr., Antonio. Antología del pensamento crítico brasileño contemporâneo. Buenos Aires: Clacso, p.123-138.

Bastos, Elide Rugai. (20I5a). Sessenta anos da publicação de um relatório exemplar. Sinais Sociais, 1o/28, p. 29-54.

Bastos, Elide Rugai. (20I5b). Uma sociologia local e cosmopolita. In: Chaguri, Mariana \& Medeiros, Mário (orgs.). Rumos do Sul. Periferia e pensamento social. São Paulo: Alameda, p. I7-32.

Bastos, Elide Rugai. (20II). Atualidade do pensamento social brasileiro. Sociedade \& Estado, 26/2, p. 5I-70.

Bastos, Elide Rugai. (2002). Pensamento social da Escola Sociológica Paulista. In: Miceli, Sergio (org.). O que ler na ciência social brasileira - 1997-2002. São Paulo/Brasília: Editora Sumaré/Anpocs-Capes, p. I83-230. 
Bastos, Elide Rugai. (1984). As Ligas Camponesas. Petrópolis: Vozes.

Botelho, André. (2019). O retorno da sociedade. Política e interpretações do Brasil. Petrópolis: Vozes.

Botelho, André \& Brasil Jr., Antonio. (2020). Prefácio: A revolução burguesa no Brasil: cosmopolitismo sociológico e autocracia burguesa. In: Fernandes, Florestan: A revolução burguesa no Brasil. São Paulo/Curitiba: Contracorrente/Kotter Editorial (no prelo).

Campos, Antônia Junqueira Malta. (2013). Interfaces entre sociologia e processo social. Dissertação de Mestrado. PPGS/ Universidade Estadual de Campinas.

Candido, Antonio. (I98I) [1959]. Formação da literatura brasileira. 6 ed. Belo Horizonte: Itatiaia.

Cohn, Gabriel. (2015). Florestan Fernandes: grandes problemas, grandes interlocutores. In: Cepeda, Vera Alves \& Mazucato, Thiago (orgs.). Florestan Fernandes: 20 anos depois - um exercício de memória. São Carlos: Ed. Ufscar, p. 23-46.

Fernandes, Florestan. (1979) [1976]. Circuito fechado: quatro ensaios sobre o "poder institucional". 2 ed. São Paulo: Hucitec. Fernandes, Florestan. (1978). A condição de sociólogo. São Paulo: Hucitec.

Fernandes, Florestan. (1976a) [1975]. A revolução burguesa no Brasil. Ensaio de interpretação sociológica. 2 ed. Rio de Janeiro: Zahar Editores.

Fernandes, Florestan. (1976b) [1962]. A sociologia numa era de revolução social. 2 ed. reorganizada e ampliada. Rio de Janeiro: Zahar Editores.

Fernandes, Florestan. (I970). A concepção de ciência política de K. Mannheim. In: Elementos de sociologia teórica. São Paulo: Editora da USP/Companhia Editora Nacional, p. 223-238.

Fernandes, Florestan. (1967) [1959]. Fundamentos empíricos da explicação sociológica. 2 ed. São Paulo: Editora Nacional. Fernandes, Florestan. (1965). A integração do negro na sociedade de classes. São Paulo: Dominus Editora/Editora da USP. Fernandes, Florestan. (1960). Mudanças sociais no Brasil. São Paulo: Difusão Europeia do Livro. 
Fernandes, Florestan. (I959). Atitudes e motivações desfavoráveis ao desenvolvimento. In: Costa Pinto. Resistências à mudança - fatores que impedem ou dificultam o desenvolvimento. Anais do Seminário Internacional. Rio de Janeiro: Centro Latino-americano de Pesquisas em Ciências Sociais, p. 219-259.

Freyre, Gilberto. (1933). Casa-grande \& senzala. Formação da família brasileira sob o regime de economia patriarcal. Rio de Janeiro: Maia \& Schmidt.

Furtado, Celso. (2005) [I959]. Formação econômica do Brasil. São Paulo: Companhia Editora Nacional.

Goldmann, Lucien. (1959) [1955]. Le Dieu caché. Paris: Gallimard.

Merton, Robert K. (1964). Teoría y estructura sociales. Trad. Florentino M. Torner. Ciudad de México: Fondo de Cultura Económica.

Prado Jr., Caio. (I972) [1942]. Formação do Brasil contemporâneo. I2 ed. São Paulo: Editora Brasiliense.

Rosa, Ana Beatriz. (2019). Diferença de salários entre negros e brancos do Brasil é de 73,9\%, aponta o IBGE. Disponível em $<$ http://www.ihu.unisinos.br/78-noticias/594353-diferenca-de-salarios-entre-negros-e-brancos-do-brasil-e-de-73-9-aponta-ibge>. Acesso em 2I maio 2020.

Silva, Mário Augusto Medeiros da. (2013). A descoberta do insólito: literatura negra e literatura periférica no Brasil. Rio de Janeiro: Aeroplano. 


\section{A HISTÓRIA NUNCA SE FECHA}

Resumo

O artigo analisa como a expressão circuito fechado usada por Florestan Fernandes assume posição central em seus estudos sobre a sociedade brasileira, constituindo-se em um dos apoios teórico-metodológicos de sua reflexão. Assim, sua utilização proporciona o questionamento de vários ângulos utilizados na interpretação do Brasil: a visão linear da história, a ideia de dualismo do país, a proposta analítica de formação, a aceitação da autonomia das instituições. Florestan Fernandes prioriza a pergunta sobre os efeitos sociais e políticos advindos de uma formação econômico-social na periferia do capitalismo, formação peculiar, pois não apenas soma, mas combina, na manutenção de seu perfil, modernidade e arcaísmos. A pergunta sobre a coexistência no Brasil do capitalismo moderno e da desigualdade, que limita o acesso aos direitos políticos e sociais, o induz a avançar tanto no estudo dos grupos como das modalidades de ação. O artigo indaga, ainda, sobre a pertinência da utilização dessa expressão para enfocar os embates sociais e políticos contemporâneos.

\section{HISTORY NEVER CLOSES}

Abstract

The article analyses the central role played by the term allows him to question different approaches used for interpreting Brazil: the linear vision of history, the idea of Brazil's dualism, the analytical proposition based on the notion of formation, the acceptance of the autonomy of institutions. The article also asks whether the term is pertinent to contemporary social and political conflicts.
Palavras-chave

Circuito fechado;

dualismo;

formação;

institucionalização;

Florestan Fernandes.

\section{Keywords}

Closed circuit;

dualism;

formation;

institutionalization;

Florestan Fernandes. 